\title{
EXPLORING THE RELATIONSHIP BETWEEN FOOD INSECURITY WITH HUNGER AND ACADEMIC PROGRESSION AT A LARGE SOUTH AFRICAN UNIVERSITY
}

\author{
F. Wagner* \\ https://orcid.org/0000-0002-1599-3485
}

\author{
T. Kaneli* \\ https://orcid.org/0000-0001-9479-5868
}

\section{Masango* \\ https://orcid.org/0000-0002-0220-8281}

*Analytics and Institutional Research Unit

University of the Witwatersrand

Johannesburg, South Africa

\section{ABSTRACT}

Food insecurity has been recognized as one of the key challenges currently affecting students in higher education. However, there has been limited research in South African higher education that has sought to understand the relationship between food insecurity and student success. The current study defined student success as a student meeting the requirements to progress from one year of study to another. The study aimed to understand the relationship between food insecurity and student academic progression. Further to this, it aimed to understand the prevalence of food insecurity, and the characteristics of students most likely to progress. This study was carried out at a large South African university and targeted at the entire 2019 first-time, first year undergraduate student cohort $(n=5356)$. All eligible students were invited via email to participate in a self-administered, online cross-sectional survey. The Household Food Insecurity Access Scale (HFIAS) was used to measure student food insecurity. Data were linked to the end of the year academic progress outcomes, which indicated whether or not students had met the requirements to progress to the following year of study. The survey was completed by 1612 students, giving a 30 per cent response rate. Overall, nearly a quarter of the students $(23 \%)$ were found to be experiencing food insecurity with hunger, with 5 per cent experiencing severe hunger. A retention rate of 94 per cent was recorded, and a little over 70 per cent of participants progressed to the second year of study. Student academic progression was found to be significantly associated with food security status $(p<0.001)$, as well as first generation status $(p=0.007)$ and home location $(p<0.001)$ in the bivariate analysis. Further to this, a multivariate analysis revealed that students experiencing little to no hunger were almost twice as likely to progress to the next year of study when compared to those experiencing food insecurity with hunger (Odds Ratio 
$[O R]=1.876 ; 95 \%$ Confidence Interval $[\mathrm{Cl}]$ : 1.454-2.418; $p<0.001)$. The results of this study demonstrated that food insecurity with hunger was negatively associated with student academic progression. This is one of the first, and largest, South African studies to demonstrate this relationship. This work advocates for students experiencing food insecurity with hunger to be prioritised in university student support programmes, such as food security interventions, as this may improve student success.

Keywords: food insecurity, academic progression, student success, hunger, higher education institutions, South Africa, university

\section{INTRODUCTION}

Food insecurity among students is a growing concern in South African Higher Education Institutions (HEI's). Studies conducted in the past few years have reported alarming rates of food insecurity (Munro et al. 2013; Sabi et al. 2019; Van den Berg and Raubenheimer 2015; Rudolph et al. 2018; Kassier and Veldman 2013).

Food insecurity is often erroneously thought to be synonymous with hunger (Forman et al. 2018). Food insecurity is certainly related to hunger, however, hunger, refers to a physical feeling and is described by the Food and Agriculture Organisation (FAO) as "an uncomfortable or painful sensation caused by insufficient food energy consumption" (FAO 2008, 3). Unlike hunger, food insecurity is not a physical feeling, but is rather a term that is used to describe insufficient access to food that is nutritious, safe, and meeting special dietary requirements (FAO 1996). Therefore, food insecurity heightens the risk of hunger.

Research studies conducted to-date in HEI's have consistently identified students' socioeconomic status as a critical contributor to food insecurity (Munro et al. 2013; Sabi et al. 2018; 2019; Van den Berg and Raubenheimer 2015; Rudolph et al. 2018; Kassier and Veldman 2013). These studies have found that students who are recipients of funding from the National Student Financial Aid Scheme (NSFAS) are at heightened risk of being food insecure when compared to students not receiving NSFAS support (Munro et al. 2013). The NSFAS targets its funding primarily at students coming from working class and poor families (NSFAS 2020).

As a result of the increasing number of students receiving NSFAS funding year on year (NSFAS 2018, 22), HEI's are becoming increasingly accessible to students from low income households, which have a higher likelihood of being severely food-insecure. Such students may lack secure and sufficient financial resources for food. According to research, even though this group of students receives NSFAS support, they are still at a higher risk of food insecurity compared to their peers who do not receive assistance (Sabi et al. 2019; Munro et al. 2013).

International literature exploring links between food insecurity and academic outcomes exists. The prevalence of food insecurity in HEI's is generally lower in the United States of 
America (USA) when compared to South Africa, with food insecurity rates ranging from 19 per cent to 35 per cent reported in some studies (Van den Berg and Raubenheimer 2015; El Zein et al. 2019; Morris et al. 2016). Similar to South Africa, students found to be food insecure were likely to be receiving financial support through loan facilities (Morris et al. 2016) and were likely to be Black or Hispanic (El Zein et al. 2019).

In their conceptual framework, Sorhaindo and Feinstein $(2006,6)$, reported that nutrition can impact: 1) cognition - including attention span, memory, concentration; 2) behaviour including increased aggression and hyperactivity, and 3) physical development - including reduced body mass index and impaired motor skills. Food insecurity especially with hunger, is known to have compounded adverse effects on student learning and wellbeing; students who are hungry often exhibit psychosomatic symptoms, including depression, dizziness, headaches and irritability (Pickett, Michaelson, and Davison 2015, 529), which may lead to poor concentration and low content uptake during learning.

Gaining insights on the links between student food insecurity and student success is imperative, as it is unclear whether the food insecurity of students contributes to South African HEI's continued struggle with low student success rates. The South African Department of Education and Training's (DHET) cohort analyses report released in 2019 suggests that 71 per cent of the student cohort enrolled for 3 year degrees in the 2015 student cohort failed to graduate in minimum time (DHET 2019a, 57). As a result, the Department has called for more research to be conducted by HEI's to understand the possible contributors to the persisting low success rates.

In order to determine the impact of food insecurity on student success, there is a need to define what is meant by student success in the context of this article. Although there is no agreed upon definition of student success, there is consensus that student success represents concepts of student retention, progression and throughput (Cele 2021, 57). In this article, the definition of student success was limited only to student academic progression. Student academic progression was defined as a "student progressing from one academic level to the next" (Nettles et al. 1999, 61). A student was determined as "successful" if they have met the requirements to progress from year of study one to year of study two.

\section{PROBLEM STATEMENT AND RESEARCH QUESTIONS}

Despite the pervasiveness of food insecurity in South African HEI's, its effects on student success is still not well understood. Current evidence coming from studies conducted in South African HEI's suggests that students perceive food insecurity as negatively impacting their ability to learn (Sabi et al. 2019); however, there has been limited work that has objectively 
explored the relationship between food insecurity and student academic progress in the South African context. A limited understanding of the impact of food insecurity on student success means that HEI's are unable to give students the support they need.

This study therefore aimed to answer the following questions: What is the relationship between food insecurity and student success? What is the prevalence of food insecurity among first year undergraduate (UG) students in a large South African university? What are the characteristics of students who are likely to progress academically?

\section{METHODS}

\section{Study setting and design}

This study was carried out at a large South African university, with data collected over 6 weeks starting in September 2019. In 2019, the student body of the university was made up of approximately 40000 students, of which 37 per cent were postgraduate students and 55 per cent were female. This study focused on the entire first-time entering first year UG student cohort, which made up 13 per cent of the student population (5356). The study was incorporated into the online, self-administered First Year Student Satisfaction Survey targeted at the same first year population.

\section{Study participants and recruitment}

Students were eligible to participate if they were UG, first-time entering first year students in 2019, over the age of 18 years and enrolled as full-time students. All eligible students were recruited via email, with each email containing a unique link directing them to the online survey.

\section{Data collection tools}

The Household Food Insecurity Access Scale (HFIAS) was used to measure food insecurity. The tool was adapted so it would be applicable to both students living in the university residence context as well as those that may have been living off-campus. The HFIAS is a standardised 9item scale with international applicability (Coates, Swindale, and Bilinsky 2007), and includes a 3-item Household Hunger Scale (HHS) (Ballard et al. 2011). Following data collection, reports from the university data warehouse were extracted using individual identifiers of those that completed the survey. Oracle's OBIEE software (California, USA) was used to extract these reports which contained student demographic information, as well as student academic progress outcomes. 


\section{Measuring student academic progression}

At the end of each academic year and based on their academic performance, each student registered at the university and pursuing an academic programme, is assigned a progress code. Academic progression was defined as a student in year of study 1 (YOS 1) meeting all the requirements to advance to year of study 2 (YOS 2). Respondents' progress codes were therefore grouped the into two categories: 1) Progression to YOS 2 and 2) No Progression to YOS 2.

\section{Data collection and analyses}

Survey data were collected using Research Electronic Data Capture (REDCap) hosted at the University of the Witwatersrand, Johannesburg (Harris et al. 2019; 2009). Data from REDCap were merged with reports from OBIEE and analysed using STATA SE 14 (StataCorp LLC).

\section{Ethical considerations}

The study received ethical clearance from the University of the Witwatersrand Human Research Ethics Committee (HREC) (Medical), Clearance Certificate (M210712), as well as (Nonmedical), Clearance Certificate (H18/09/17). In addition, permission was received from the Office of the Registrar to conduct the study.

\section{RESULTS}

Of the participants invited to respond, 30 per cent (1 612 students) completed the survey. Table 1 presents the demographics of students who participated in the survey. The age distribution ranged from 18 to 39 years, with a median of 19 years. Students participating in the study were mostly South African (94\%), female (62\%), in terms of race, were mostly African (75\%), and most were studying towards a qualification in the humanities faculty (31\%). Most students described the location of their homes as being in the City or Suburb (44\%) or in the Township (32\%), with 45 per cent receiving financial support from NSFAS and 48 per cent being first in their family to go to university.

Table 2 shows that 73 per cent of the students were food insecure. Food insecurity was distributed among those that were mildly food insecure (11\%), moderately food insecure (24\%) and severely food insecure (38\%). Of the students participating in the study, 77 per cent experienced little to no hunger, 18 per cent experienced moderate hunger and 5\% experienced severe hunger. An analysis of food insecurity together with hunger revealed that nearly a quarter of the students were experiencing food insecurity with hunger (23\%). 
Table 1: Demographic attributes of students participating in the study

\begin{tabular}{|c|c|c|}
\hline Demographic tables $(n=1612)$ & $\mathbf{n}$ & $\%$ \\
\hline \multicolumn{3}{|l|}{ Gender: } \\
\hline Female & 1003 & 62 \\
\hline Male & 609 & 38 \\
\hline \multicolumn{3}{|l|}{ Race: } \\
\hline African & 1206 & 75 \\
\hline Chinese & 7 & 0 \\
\hline Coloured & 44 & 3 \\
\hline Indian & 164 & 10 \\
\hline Unknown & 10 & 1 \\
\hline White & 181 & 11 \\
\hline \multicolumn{3}{|l|}{ Nationality: } \\
\hline South African & 1508 & 94 \\
\hline International & 104 & 6 \\
\hline \multicolumn{3}{|l|}{ Faculty: } \\
\hline Faculty of Commerce, Law \& Management & 265 & 16 \\
\hline Faculty of Engineering and the Built Environment & 298 & 19 \\
\hline Faculty of Health Sciences & 253 & 16 \\
\hline Faculty of Humanities & 500 & 31 \\
\hline Faculty of Science & 296 & 18 \\
\hline \multicolumn{3}{|l|}{ Home Location: } \\
\hline Rural Village or Farm & 345 & 21 \\
\hline Informal Settlement & 47 & 3 \\
\hline Township & 517 & 32 \\
\hline City/ Suburb & 703 & 44 \\
\hline \multicolumn{3}{|l|}{ NSFAS Bursary: } \\
\hline Yes & 723 & 45 \\
\hline No & 889 & 55 \\
\hline \multicolumn{3}{|l|}{ First-Generation Status: } \\
\hline Yes & 781 & 48 \\
\hline No & 831 & 52 \\
\hline
\end{tabular}

Table 2: Distribution of food insecurity and hunger prevalence among students

\begin{tabular}{|c|c|c|}
\hline Food Security and Hunger Status & $\mathbf{n}$ & \% \\
\hline HFIA Scale: & & 27 \\
\hline Food Secure & 431 & 11 \\
\hline Mildly food insecure & 186 & 24 \\
\hline Moderately food insecure & 386 & 38 \\
\hline Severely food insecure & 609 & $\mathbf{1 0 0}$ \\
\hline Total & $\mathbf{1 6 1 2}$ & 77 \\
\hline Hunger Scale: & & 18 \\
\hline Little to no hunger & 1236 & 5 \\
\hline Moderate hunger & 296 & $\mathbf{1 0 0}$ \\
\hline Severe hunger & 80 & 27 \\
\hline Total & $\mathbf{1 6 1 2}$ & 59 \\
\hline Food Security and Hunger: & & 23 \\
\hline Food secure & 431 & $\mathbf{1 0 0}$ \\
\hline Food insecure without hunger & 805 & \\
\hline Food insecure with hunger & 376 & $\mathbf{1 6 1 2}$ \\
\hline Total & & \\
\hline
\end{tabular}

Results presented in Figure 1 compare the progression and retention rates of the study participants to the entire first-time entering first year UG student cohort of 2019. In terms of progression, a higher percentage of study participants (72\%) progressed compared to the entire 
first year UG student cohort (66\%). Furthermore, the student retention rate suggested that study participants had a slightly higher retention rate (94\%) when compared to the first year UG student cohort (90\%).

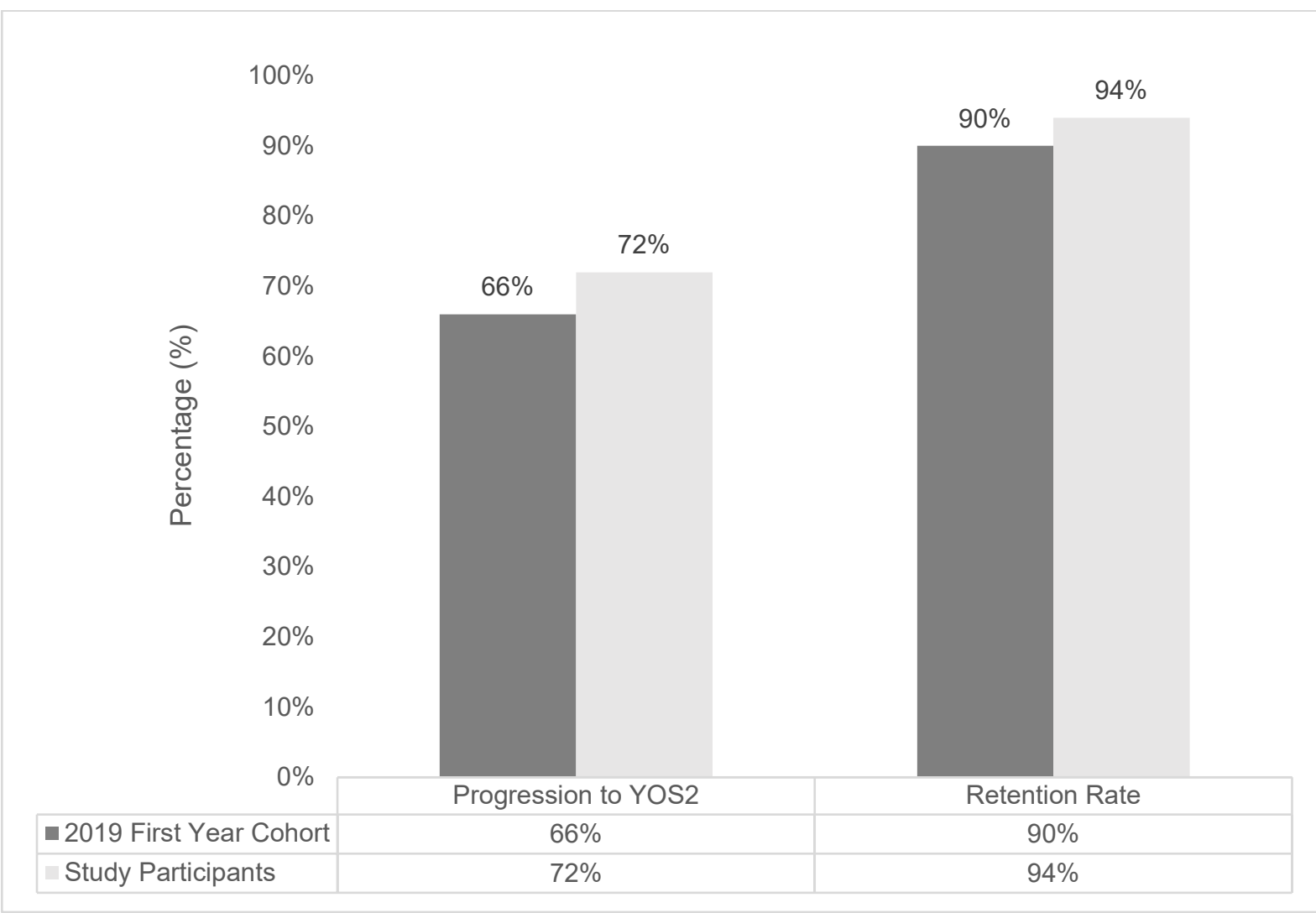

Figure 1: Progression and retention rates of study participants when compared to the entire 2019 first year UG student cohort.

The chi-square test of independence was used to determine the nature of the relationship between student retention (whether or not a student re-registered in the subsequent year, 2020) and a number of variables. Results in Table 3 indicate that only gender $(p=0.005)$ and working for pay ( $p=0.019$ ) were significant in their association with student retention, and all the other variables including food security status and hunger were not significant.

Table 3: Chi-square test of independence for student retention and socio-demographic variables

\begin{tabular}{|l|c|c|}
\hline \multicolumn{1}{|c|}{ Variable } & $\mathbf{X}^{\mathbf{2}}$ & $\boldsymbol{p}$ \\
\hline Food security status & 3.987 & 0.263 \\
\hline Hunger status & 3.556 & 0.169 \\
\hline Race & 0.947 & 0.967 \\
\hline Gender & 7.928 & 0.005 \\
\hline Home location & 2.428 & 0.488 \\
\hline Working for pay & 5.491 & 0.019 \\
\hline NSFAS funded & 2.023 & 0.155 \\
\hline First generation status & 0.2778 & 0.598 \\
\hline
\end{tabular}


The chi-square test of independence was used to determine the nature of the relationship between student progression and a number of variables. Table 4 shows that food security status, hunger status, race, gender and home location were significant $(p<0.001)$ in their association with student progression. Whether or not a student was first in their family to attend university (first generation status) was also significant $(p=0.007)$.

Table 4: Chi-square test of independence for student progression to YOS 2 and socio-demographic variables

\begin{tabular}{|l|c|c|}
\hline \multicolumn{1}{|c|}{ Variable } & $\mathbf{X}^{\mathbf{2}}$ & $\boldsymbol{p}$ \\
\hline Food security status & 53.2443 & $<0.001$ \\
\hline Hunger status & 43.943 & $<0.001$ \\
\hline Race & 38.32 & $<0.001$ \\
\hline Gender & 16.432 & $<0.001$ \\
\hline Home location & 43.411 & $<0.001$ \\
\hline Working for pay & 0.254 & 0.615 \\
\hline NSFAS funded & 0.078 & 0.790 \\
\hline First generation status & 7.397 & 0.007 \\
\hline
\end{tabular}

Student progression had several significant associations. A multivariate analysis was then performed to ascertain the combined effect of the variables of interest, which were food security status, hunger status, race, gender, home location and first-generation status, on the student progression outcome. Table 5 summarises the logistic regression model results.

Table 5: Backward stepwise regression of factors associated with student progression to YOS 2 (multivariate analysis)

\begin{tabular}{|c|c|c|c|c|}
\hline Variable of Interest & $\begin{array}{l}\text { Progression to } \\
\text { YOS } 2(\%)\end{array}$ & $\begin{array}{c}\text { No Progression } \\
\text { to YOS } 2(\%)\end{array}$ & Odds Ratio (95\% CI) & $p$-value \\
\hline \multicolumn{5}{|l|}{ Gender: } \\
\hline Male & $404(66)$ & $205(34)$ & 1 & \\
\hline Female & $759(76)$ & $244(24)$ & $1.381(1.096-1.739)$ & 0.006 \\
\hline \multicolumn{5}{|l|}{ Hunger Status: } \\
\hline Hunger & $221(59)$ & $155(41)$ & 1 & \\
\hline Little to no hunger & $942(76)$ & $294(24)$ & $1.876(1.454-2.418)$ & $<0.001$ \\
\hline \multicolumn{5}{|l|}{ Race: } \\
\hline African & $828(69)$ & $378(31)$ & 1 & \\
\hline Chinese & $7(100)$ & 0 & - & \\
\hline Coloured & $32(73)$ & $12(27)$ & $0.946(0.470-1.907)$ & 0.887 \\
\hline Indian & $128(78)$ & $36(22)$ & $1.091(0.704-1.693)$ & 0.696 \\
\hline White & $161(89)$ & $20(11)$ & $2.510(1.485-4.241)$ & 0.001 \\
\hline Race unknown & $7(70)$ & $3(30)$ & $0.900(0.227-3.566)$ & 0.881 \\
\hline \multicolumn{5}{|l|}{ Home Location: } \\
\hline Rural Village or Farm & $208(60 \%)$ & $137(40 \%)$ & 1 & \\
\hline Informal Settlement & $32(68 \%)$ & $15(32 \%)$ & $1.407(0.727-2.721)$ & 0.311 \\
\hline Township & $365(71 \%)$ & $152(29 \%)$ & $1.541(1.150-2.064)$ & 0.004 \\
\hline City/ Suburb & $558(79 \%)$ & $145(21 \%)$ & $1.743(1.255-2.419)$ & 0.001 \\
\hline
\end{tabular}


The variables of interest demonstrated a relationship with student progression on their own (Table 4). However, in the multivariate regression several variables which were found significant in the bivariate analysis were no longer significant (Table 5).

The multivariate model suggests that students experiencing little to no hunger $(\mathrm{OR}=$ 1.876; 95\% CI 1.454-2.418; $p<0.001$ ) were almost twice as likely to progress to the next year of study when compared to those experiencing food insecurity with hunger (Table 5). This group of students was likely to be white $(\mathrm{OR}=2.510 ; 95 \% \mathrm{CI} 1.485-4.241 ; p=0.001)$, female $(\mathrm{OR}=1.381 ; 95 \%$ CI $1.096-1.739 ; p=0.006)$ and students whose homes were located in the City/Suburb (OR=1.743 95\% CI 1.255 - 2.419; $p=0.001)$.

\section{DISCUSSION}

Food insecurity has been recognized as one of the key challenges currently affecting students in higher education (Munro et al. 2013; Sabi et al. 2019; Van den Berg and Raubenheimer 2015; Rudolph et al. 2018; Kassier and Veldman 2013). South Africa has over 1 million students in its HEI's (DHET 2019b, 3). The government continues to implement policies that are targeted at previously disadvantaged groups (NSFAS 2018). This has resulted in HEI's having demographics similar to the one presented in Table 1, where most students, similar to those who participated in this study, are African and female (DHET 2019b, 11; Moses, Van Der Berg, and Rich 2017, 23).

In the current study, the prevalence of food insecurity was found to be 73 per cent, with almost a quarter of these students (23\%) experiencing food insecurity with hunger, and 5 per cent experiencing severe hunger (Table 2). These prevalence figures are slightly lower than those published by another South African study which reported food insecurity prevalence as high as 84 per cent when using a multi-item measure of food insecurity, with 60 per cent of the students experiencing food insecurity with hunger (Van den Berg and Raubenheimer 2015). On the other hand, the food insecurity findings from the current study were comparatively high when compared to those presented by Rudolph et al. (2018), who reported food insecurity with hunger at 7 per cent. The discrepancy can be attributed to 1) the two studies targeted different populations, with the current study focusing only on first-time entering first year UG students and Rudolph et al. (2018) focusing on the entire UG cohort; 2) the data was collected in different years, with data for this study collected in late 2019, and Rudolph et al. (2018) in the previous years; and 3) difference in approaches with this study targeting the entire cohort and reaching 30 per cent of first-time entering students and Rudolph et al. (2018) whose sample reached 1 per cent of the population of interest (first year UG students).

The first year of study is widely regarded as crucial to a student's academic performance 
(Nelson, Duncan, and Clarke 2009). As such, poor experiences during this year have been linked with a higher likelihood of student dropout, hence the often low retention rates and low progression rates in the first year of study (Nelson, Duncan, and Clarke 2009). The retention rates of 94 per cent for the study participants (Figure 1) were slightly higher than the national averages reported by the DHET, (2019a, 57) which indicated drop-out rates of 12-13 per cent (i.e., retention rates of $88-87 \%$ ) for study programmes that were 3 years and longer. This could be attributed to the responsive support programmes provided to the first year students by this university. It is worth noting that students that were not retained may have enrolled in other institutions. The progression rate of participants reported in this study was 72 per cent (Figure 1), there are limited studies that have explored the year to year progression rates of students (Robinson 2004); however, reports from the DHET (2019a, 57-81) indicate that only 29-38 per cent of graduates complete in minimum time.

When exploring the relationship between food insecurity and student success, student retention was found to not be associated with food security status and hunger (Table 3 ). In addition, the bivariate analysis indicated that only gender and working for pay were significant in their association with student retention. However, student academic progression was found to be significantly associated with food security status (Table 4). To our knowledge, the current study is one of the first in South Africa that has found significant links between food security and student progression.

Similar studies conducted in the USA have also found clear links between student food insecurity and their academic outcomes. These studies have shown that food insecure students have a higher likelihood to perform poorly academically and take longer to graduate when compared to food secure students (El Zein et al. 2019; Morris et al. 2016). Food insecure students were also shown to have a higher likelihood of scoring lower grade point averages (GPA's) when compared to their food secure counterparts (El Zein et al. 2019; Morris et al. 2016). Furthermore, students experiencing food insecurity were more likely to experience higher levels of stress, had an increased likelihood of experiencing poor sleep and inconsistent eating patterns when compared to their food secure counterparts (El Zein et al. 2019).

In addition to food security status, student academic progression was found to be significantly associated with first generation status and home location in the bivariate analysis (Table 4). Other South African studies had similar findings, these studies found that being a first generation student (Van den Berg and Raubenheimer 2015) and originating from a township (Rudolph et al. 2018) predicted food insecurity. According to (Selesho 2012; WilsonStrydom 2010), students who are first generation have more difficulty integrating into their new university environment. This suggests that success may improve when students have the 
support of someone who has been in university. The area which the student is from, including the location and socio-economic status of their communities, has been shown to be a risk factor, with students from some provinces (e.g., Gauteng) and areas (e.g., upmarket areas such as Suburbs and Cities) thought to have a higher likelihood of success (Hundermark 2018). Students from low-income families face financial difficulties, such as difficulties obtaining funds to pay university fees, food, housing, and other requirements such as clothing; these students have been found to be more stressed during their studies (Bojuwoye 2002).

In the current study, the multivariate analysis revealed that students experiencing little to no hunger were almost twice as likely to progress to the next year of study when compared to those experiencing food insecurity with hunger (Table 5). Students experiencing little to no hunger were likely to be white, female with homes were located in the City/Suburb. These results are in agreement with the findings reported in other studies. Studies carried out in South African HEI's, which have generally aimed to investigate the predictors of food insecurity in student populations, have found that African students who are male (Van den Berg and Raubenheimer 2015; Rudolph et al. 2018), pursuing undergraduate studies (Van den Berg and Raubenheimer 2015), and those on extended programmes, in particular (Munro et al. 2013), are more likely to be food insecure.

Unlike in the bivariate analysis, general food security status was found not to be significant in the regression model (Table 5). However, hunger status, which denotes a more severe kind of food insecurity, remained a strong predictor of student progression as demonstrated in the multivariate analysis. The Hunger Scale (Ballard et al. 2011) classifies individuals as experiencing food insecurity with hunger, based on their experience of any (or all) of the following:

(i) "having no food, of any kind in the house, to eat because of lack of resources to get food";

(ii) "going to bed hungry because there was not enough food"; and

(iii) "going a whole day and night without eating anything because there was not enough food".

This suggests that students who experienced food insecurity with hunger, answering "yes" to the questions above, were less likely to progress when compared with students that did not experience hunger, irrespective of their food security status.

\section{LIMITATIONS}

The current study used the HFIAS to measure student food insecurity. This tool measures food security and hunger over the past 30 days. Other studies, with similar aims have used these tools (Kassier and Veldman 2013), and we assume that the results reflect the food security status of 
a student in a typical month.

The socio-economic status of students was not directly measured in the study; however, home location was used as a proxy. Future work exploring the best indirect measure of a students' socio-economic status is warranted.

\section{CONCLUSION}

The findings from this study demonstrate that food insecurity with hunger is adversely associated with student academic progression. Students experiencing little to no hunger, irrespective of their food security status, had a higher likelihood of progressing academically, when compared to those who experience food insecurity with hunger. To our knowledge, this is one of the first and largest South African study to demonstrate this relationship. Food insecurity with hunger and its relationship with student success, especially during the first year of study, should be considered as a priority by HEI's.

This work advocates for students experiencing food insecurity with hunger to be prioritised in university student support programmes, such as food security interventions, as this may improve student success. The findings of the current study can be used to inform the formulation of university policies when addressing the challenge of food insecurity with hunger among students.

\section{REFERENCES}

Ballard, Terri, Jennifer Coates, Anne Swindale, and Megan Deitchler. 2011. "Household Hunger Scale (HHS): Indicator Definition and Measurement Guide | Food and Nutrition Technical Assistance III Project (FANTA)." https://www.fantaproject.org/monitoring-and-evaluation/householdhunger-scale-hhs.

Bojuwoye, O. 2002. "Stressful Experiences of First Year Students of Selected Universities in South Africa." Counselling Psychology Quarterly. Taylor \& Francis Group. https://doi.org/ 10.1080/09515070210143480.

Cele, N. 2021. "Big Data-Driven Early Alert Systems as Means of Enhancing University Student Retention and Success." South African Journal of Higher Education 35(2): 56-72. https://doi.org/ 10.20853/35-2-3899.

Coates, Jennifer, Anne Swindale, and Paula Bilinsky. 2007. "Household Food Insecurity Access Scale (HFIAS) for Measurement of Food Access: Indicator Guide: Version 3.” www.fantaproject.org.

Department of Education and Training. 2019a. "2000 to 2016 First Time Entering Undergraduate Cohort Studies for Public Higher Education Institutions." Pretoria. www.dhet.gov.za.

Department of Education and Training. 2019b. "Statistics on Post-School Education and Training in South Africa." Pretoria. http://www.dhet.gov.za/SiteAssets/Statistics on Post-School Education and Training in South Africa 2017.pdf.

DHET see Department of Education and Training.

El Zein, Aseel, Karla P. Shelnutt, Sarah Colby, Melissa J. Vilaro, Wenjun Zhou, Geoffrey Greene, Melissa D. Olfert, Kristin Riggsbee, Jesse Stabile Morrell, and Anne E. Mathews. 2019. "Prevalence and Correlates of Food Insecurity among U.S. College Students: A Multi-Institutional 
Study." BMC Public Health 19(1): 1-12. https://doi.org/10.1186/s12889-019-6943-6.

FAO see Food and Agriculture Organisation.

Food and Agriculture Organisation. 1996. "Rome Declaration and Plan of Action." http://www.fao.org/3/w3613e/w3613e00.htm.

Food and Agriculture Organisation. 2008. "An Introduction to the Basic Concepts of Food Security." http://www.fao.org/documents/card/en/c/2357d07c-b359-55d8-930a-13060cedd3e3/.

Forman, Michele R., Lauren D. Mangini, Yong Quan Dong, Ladia M. Hernandez, and Karen L. Fingerman. 2018. "Food Insecurity and Hunger: Quiet Public Health Problems on Campus." Journal of Nutrition \& Food Sciences 08(02): 668. https://doi.org/10.4172/2155-9600.1000668.

Harris, Paul A., Robert Taylor, Brenda L. Minor, Veida Elliott, Michelle Fernandez, Lindsay O'Neal, Laura McLeod, et al. 2019. "The REDCap Consortium: Building an International Community of Software Platform Partners." Journal of Biomedical Informatics. Academic Press Inc. https://doi.org/10.1016/j.jbi.2019.103208.

Harris, Paul A., Robert Taylor, Robert Thielke, Jonathon Payne, Nathaniel Gonzalez, and Jose G. Conde. 2009. "Research Electronic Data Capture (REDCap) - A Metadata-Driven Methodology and Workflow Process for Providing Translational Research Informatics Support." Journal of Biomedical Informatics 42(2): 377-381. https://doi.org/10.1016/j.jbi.2008.08.010.

Hundermark, Genevieve. 2018. "Who Are Our First-Year At-Risk Humanities Students? A Reflection on a First-Year Survey Administered by the Wits Faculty of Humanities Teaching and Learning Unit in 2015 and 2016." Journal of Student Affairs in Africa | 6(2): 85-97. https://doi.org/10.24085/jsaa.v6i2.3311.

Kassier, Suna and Frederick Veldman. 2013. "Food Security Status and Academic Performance of Students on Financial Aid: The Case of University of KwaZulu-Natal." Alternation 9: 248-64. http://alternation.ukzn.ac.za/Files/docs/20.6/12 Kas.pdf.

Morris, Loran Mary, Sylvia Smith, Jeremy Davis, and Dawn Bloyd Null. 2016. "The Prevalence of Food Security and Insecurity Among Illinois University Students." Journal of Nutrition Education and Behavior 48(6): 376-382.e1. https://doi.org/10.1016/j.jneb.2016.03.013.

Moses, Eldridge, Servaas Van Der Berg, and Kate Rich. 2017. "A Society Divided: How Unequal Education Quality Limits Social Mobility In South Africa." http://resep.sun.ac.za/wpcontent/uploads/2017/03/2372-Resep_PSPPD_A-society-divided_WEB.pdf.

Munro, Nicholas, Michael Quayle, Heather Simpson, and Shelley Barnsley. 2013. "Hunger for Knowledge: Food Insecurity among Students at the University of KwaZulu-Natal." Perspectives in Education 31(4): 168-179.

National Student Financial Aid Scheme. 2018. "Title Working Paper 1 Version 2 Compiled by Research and Policy Date of Publication." http://www.nsfas.org.za/content/reports/NSFAS Analysis V3 - 29032018.pdf.

National Student Financial Aid Scheme. 2020. "NSFAS." 2020. http://www.nsfas.org.za/ content/mission.html.

Nelson, K. J., M. E. Duncan, and J. A. Clarke. 2009. "Student Success: The Identification and Support of First Year University Students at Risk of Attrition." Studies in Learning, Evaluation, Innovation and Development 6(1): 1-15. http://eprints.qut.edu.au/28064.

Nettles, Michael T., Ursula Wagener, Catherine M. Millett, and Ann M. Killenbeck. 1999. "Student Retention and Progression: A Special Challenge for Private Historically Black Colleges and Universities." New Directions for Higher Education 1999(108): 51-67. https://doi.org/ 10.1002/he.10804.

NSFAS see National Student Financial Aid Scheme.

Pickett, William, Valerie Michaelson, and Colleen Davison. 2015. "Beyond Nutrition: Hunger and Its Impact on the Health of Young Canadians." International Journal of Public Health 60(5): $527-$ 538. https://doi.org/10.1007/s00038-015-0673-z. 
Robinson, Rosalie. 2004. "Pathways to Completion: Patterns of Progression through a University Degree." Higher Education 47(1): 1-20. https://doi.org/10.1023/B:HIGH.0000009803.70418.9c.

Rudolph, Michael, Florian Kroll, Evans Muchesa, Anri Manderson, Moira Berry, and Nicolette Richard. 2018. "Food Insecurity and Coping Strategies amongst Students at University of Witwatersrand." Journal of Food Security 6(1): 20-25. https://doi.org/10.12691/jfs-6-1-2.

Sabi, Stella C., Unathi Kolanisi, Muthulisi Siwela, and Denver Naidoo. 2019. "Students' Vulnerability and Perceptions of Food Insecurity at the University of KwaZulu-Natal." South African Journal of Clinical Nutrition June: 1-8. https://doi.org/10.1080/16070658.2019.1600249.

Sabi, Stella C., Muthulisi Siwela, Unathi Kolanisi, and Denver K Naidoo. 2018. "Complexities of Food Insecurity at the University of Kwazulu-Natal, South Africa: A Review." Journal of Consumer Sciences 46 (July 2017): 10-18. https://www.ajol.info/index.php/jfecs/article/view/179301.

Selesho, Jacob M. 2012. "Making a Successful Transition during the First Year of University Study: Do Psychological and Academic Ability Matter?" Journal of Social Sciences 31(1): 1-10. https://doi.org/10.1080/09718923.2012.11893009.

Sorhaindo, Annik and Leon Feinstein. 2006. What Is the Relationship between Nutrition and Learning? Journal of the HEIA Vol. 13. London. www.learningbenefits.net.

Van den Berg, Louise and J. Raubenheimer. 2015. "Food Insecurity among Students at the University of the Free State, South Africa." South African Journal of Clinical Nutrition 28(4): 160-169. https://doi.org/10.1080/16070658.2015.11734556.

Wilson-Strydom, Merridy. 2010. "Traversing the Chasm from School to University in South Africa: A Student Perspective." Tertiary Education and Management 16(4): 313-325. https://doi.org/ 10.1080/13583883.2010.532565. 